Ekuitas: Jurnal Pendidikan Ekonomi

Volume 7, Number 1, 2019, pp. 23-32

P-ISSN : 2354-6107E-ISSN : 2549-2292

Open Access: https://ejournal.undiksha.ac.id/index.php/EKU

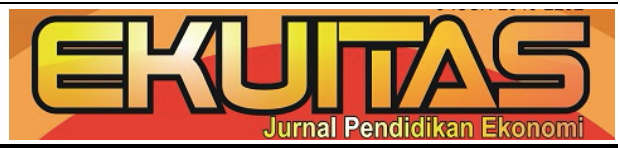

\title{
Faktor-Faktor Pemicu Minat Mahasiswa Menjadi Wirausaha (Studi Empiris di Universitas Hindu Indonesia)
}

\author{
Ni Made Wisni Arie Pramuki ${ }^{*}{ }^{*}$, Komang Ary Pratiwi $^{2}$, Putu Atim Purwaningrat ${ }^{3}$
}

1,2,3Fakultas Ekonomi UNHI, Jalan Sanggalangit, Denpasar, Indonesia

\section{A R T I C L E I N F O}

\section{Article history:}

Received 6 February 2019

Received in revised form

09 May 2019

Accepted 06 June 2019

Available online 15 June 2019

\section{Kata kunci:}

Minat Mahasiswa Menjadi

Wirausaha, Analisis Faktor

Student Interest In

Becoming Entrepreneurs,

Factor Analysis
Keywords:

\section{A B S T R A K}

Mahasiswa turut berperan serta aktif dalam pembangunan bangsa dengan suatu harapan untuk tidak sekedar sebagai pencari kerja, tetapi juga sebagai penyedia atau pencipta lapangan kerja dengan menjadi wirausaha. Masuknya kewirausahaan ke dalam kurikulum perguruan tinggi diharapkan dapat menyediakan kompetensi lulusan dengan hard skills dan softs kills kewirausahaan. Namun masih rendahnya minat mahasiswa menjadi wirausaha menjadi motivasi dan daya tarik peneliti untuk melakukan studi lanjut. Dengan demikian sangat perlu diketahui faktor-faktor yang dapat mendorong mahasiswa sebagai pemicu untuk menjadi wirausaha. Penelitian ini dilaksanakan dengan tujuan untuk mengidentifikasi faktor-faktor yang dapat memicu minat wirausaha pada mahasiswa, khususnya di Fakultas Ekonomi Universitas Hindu Indonesia. Analisis dilakukan pada data yang diperoleh dari data primer dengan menggunakn instrumen kuesioner kepada 100 mahasiswa yang meliputi analisis faktor dan analisis regresi. Dari analisa faktor diperoleh bukti bahwa faktor utama yang dapat memicu minat mahasiswa menjadi wirausaha dapat dikelompokkan menjadi tiga faktor, yaitu sikap, image dan motivasi finasnsial. Sedangkan dengan analisis regresi diperoleh bukti bahwa ketiga faktor yakni sikap, image dan motivasi finansial memiliki pengaruh positif dan signifikan terhadap minat mahasiswa menjadi wirausaha. Dengan demikian program-program kesadaran berwirausaha perlu dilaksanakan dengan lebih efisien dan efektif, sehingga generasi kita selanjutnya lebih sebagai pencipta lapangan kerja daripada pencari kerja.

\section{A B S T RAC T}

Students participate actively in the development of the nation with a hope not only as job seekers, but also as providers or creators of employment by becoming entrepreneurs. Entrepreneurship entry into the college curriculum is expected to provide graduate competencies with hardskills and entrepreneurial softskills. But the low interest of students to become entrepreneurs is the motivation and attractiveness of researchers to conduct further studies. Thus, it is very important to know what factors can encourage students as triggers to become entrepreneurs. This research was carried out with the aim to identify factors that could trigger entrepreneurial interest in students, especially at the Faculty of Economics, Indonesian Hindu University. The analysis was carried out on the data obtained from the primary data by using questionnaire instruments to 100 students which included factor analysis and regression analysis. Factor analysis test results obtained evidence that the main factors that can trigger student interest into entrepreneurship can be grouped into three factors, namely attitudes, image and financial motivation. While the regression analysis obtained evidence that the three factors namely attitudes, image and financial motivation have a positive and significant influence on the interest of students to become entrepreneurs. Thus awareness programs for entrepreneurship need to be carried out more efficiently and effectively, so that our next generation is more as a creator of employment than a job seeker. 


\section{Pendahuluan}

Isu pengangguran intelektual memberikan gambaran bahwa bagaimana tingkat pendidikan khususnya perguruan tinggi berkontribusi kepada Negara terutama dalam pengembangan industri bangsa. Sebagaimana laporan Badan Pusat Statistik (BPS) periode Februari 2018 melaporkan bahwa tingkat pengangguran terbuka (TPT) lulusan universitas mengalami kenaikan menjadi $6,31 \%$ dari sebelumnya 5,18 \% pada Februari 2017. Selain lulusan perguruan tinggi, pengangguran dari lulusan diploma I/II/III juga mengalami kenaikan sebesar 1,04 persen dari 6,88 persen. Pengangguran pada tingkat pendidikan Sekolah Dasar (SD) juga terjadi kenaikan sebesar 0,05\%. Akan tetapi dibandingkan tingkat pendidikan lainnya, pengangguran dari lulusan SD adalah yang paling sedikit. Hal ini dikarenakan bagi yang berpendidikan rendah cenderung mau menerima pekerjaan apa saja demi memenuhi kebutuhan hidupnya (Tirto.id,2018). Hal ini menjadi ironi bagaimana para lulusan perguruan tinggi (sarjana) yang seharusnya menjadi penggerak perekonomian bangsa malah menjadi pengangguran. Banyaknya pengangguran bisa jadi disebabkan oleh rendahnya kompetensi dan minimnya keahlian yang dimiliki oleh lulusan perguruan tinggi, sehingga terjadi ketimpangan antara profil lulusan universitas dengan kualifikasi tenaga kerja siap pakai yang dibutuhkan perusahaan (Kompas, 2016). Hasil survey HIPMI pada tahun 2016 juga membuktikan bahwa sebagian besar responden atau 83\% lulusan universitas setelah tamat langsung cenderung ingin mencari pekerjaan menjadi karyawan daripada menciptakan lapangan kerja dengan menjadi wirausaha. Hanya 4\% responden berminat menjadi wirausaha (Republika, 2016).

Solusi yang ditawarkan untuk mengurangi jumlah pengangguran terdidik, salah satunya adalah mempersiapkan tamatan universitas atau sarjana untuk menjadi wirausaha muda yang mandiri. Pengembangan kewirausahaan adalah unsur penting dalam perkembangan industri suatu bangsa. Tingkat kewirausahaan dapat diukur dengan melihat perkembangan ekonomi, sosial dan budaya suatu negara. Sebagian besar dari program ini bertujuan untuk keterlibatan aktif generasi muda dalam pembangunan bangsa terutama untuk menyediakan lapangan kerja.

Dalam beberapa tahun terakhir, di dunia perguruan tinggi pemerintah melalui kemenristekdikti semakin gencar mengkampanyekan dan mengembangkan arti pentingnya kewirausahaan di di kalangan mahasiswa. Kini, perkembangan kewirausahaan menjadi bagian utama kurikulum sebagian besar universitas dan perguruan tinggi di Indonesia. Sebagian besar mahasiswa di perguruan tinggi mendapatkan pengetahuan dasar mengenai kegiatan wirausaha dari lembaga masing-masing. Milla (2013) menyatakan bahwa pendidikan kewirausahaan merupakan salah satu cara untuk menciptakan suasana akademik yang kondusif berkaitan dengan pembentukan karakter mahasiswa dan lulusan perguruan tinggi. Berdasarkan modal hard skills maupun soft skills outcome dari kewirausahaan lulusan perguruan tinggi diharapkan dapat menjadi wirausaha muda yang tangguh.

Rendahnya minat menjadi wirausaha, selain faktor pendidikan dan kurikulum teknis berwirausaha, juga dipengaruhi oleh faktor internal diri mahasiswa tersebut yakni keberanian mahasiswa untuk memutuskan memulai suatu bisnis atau berwirausaha. Widhari dan Suarta (2012) membuktikan bahwa minat untuk menjadi wirausaha dipengaruhi secara signifikan oleh keberhasilan diri, toleransi resiko, dan kebebasan bekerja. Temuan ini juga didukung oleh Oktarilis (2012) yang menyatakan bahwa variabel keberhasilan diri, kebebasan dalam bekerja, dan kebutuhan prestasi berpengaruh dominan terhadap keinginan mahasiswa menjadi wirausaha.

Universitas Hindu Indonesia khususnya Fakultas Ekonomi selama ini sudah menerapkan dan mengajarkan mata kuliah kewirausahaan bahkan juga sudah dibentuknya laboratorium kewirausahaan serta aktivitas-aktivitas yang lain dalam mendukung wirausaha di kalangan mahasiswa. Namun demikian, sepengetahuan peneliti, sampai saat ini belum ada suatu kajian yang meneliti faktor-faktor yang mempengaruhi minat wirausaha pada mahasiswa, khususnya di Universitas Hindu Indonesia. Dengan demikian, penting untuk mengetahui sifat dan tingkat minat mahasiswa menjadi wirausaha. Tujuan penelitian ini dilakukan dengan tujuan untuk mengkaji faktor-faktor yang mempengaruhi minat mahasiswa menjadi wirausaha terutama di Universitas Hindu Indonesia.

\section{Metode}

Penelitian ini merupakan katagori penelitian lapangan dimana peneliti merupakan bagian dari penelitian karena ada interaksi dengan responden sebagai unit analisis penelitian. Penelitian ini juga merupakan descriptive research karena tujuan penelitian ini adalah untuk memaparkan faktor-faktor yang mempengaruhi minat mahasiswa menajadi wirausaha.

Penelitian ini didasarkan pada data primer dan sekunder. Data primer dikumpulkan menggunakan kuesioner kepada mahasiswa dari berbagai jurusan di Fakultas Ekonomi Universitas Hindu Indonesia 
yang dilaksanakan pada bulan Agustus sampai September 2018. Sampel dari 100 mahasiswa dipilih secara acak yang bertujuan untuk mengumpulkan data primer. Data sekunder dikumpulkan dari berbagai sumber seperti jurnal, majalah, buku, situs web dan sebagainya. Instrumen penelitian berupa kuesioner yang dikembangkan dari Antoni (2018) dengan menggunakan 9 indikator yang membentuk konstruk niat menjadi wirausaha. Selanjutnya penyusunan kuisioner yang terbagi dalam dua (2) bagian yakni: (1) Bagian pertama menanyakan mengenai profil responden dengan mengisi faktor demografi seperti jenis kelamin dan jurusan., (2) Bagian kedua untuk mengidentifikasi minat responden untuk menjadi wirausaha yang diberikan dalam bentuk skala likert.

Pembagian kuisioner dilakukan pada dua (2) jurusan yakni jurusan manajemen dan jurusan akuntasi. Jumlah kuisioner yang kembali sebanyak 100 lembar dengan perrincian jurusan manajemen 36 orang dan jurusan akuntansi 64 orang. Alat statistik seperti ANOVA dan Analisis Faktor digunakan untuk analisis dan uji hipotesis.

\section{Hasil dan pembahasan}

Statistik Deskriftif

Analisis deskriptif bertujuan untuk memberikan gambaran bagi suatu data yang telah dikumpulkan. Analisis ini dilakukan terhadap 100 responden yang mengisi kuisioner dengan lengkap. Rekapitulasi hasil pengumpulan data pada kuisioner bagian pertama mengenai profil responden ditampilkan di Tabel 1 dapat dijelaskan sebagai berikut bahwa jenis kelamin responden adalah 43\% mahasiswa laki-laki dan 57\% perempuan. Responden terbanyak adalah mahasiswa jurusan Akuntansi sebesar 64\%, hal ini dikarenakan peneliti juga sebagai pengajar di prodi akuntansi sehingga lebih memudahkan dalam memperoleh mahasiswa yang mengisi kuisioner baik di saat perkuliahan, maupun di luar jam perkuliahan. Sedangkan untuk jurusan manajemen, peneliti mengalami keterbatasan waktu saat mengambil sendiri data kuisioner.

Tabel 1.

Profil Responden

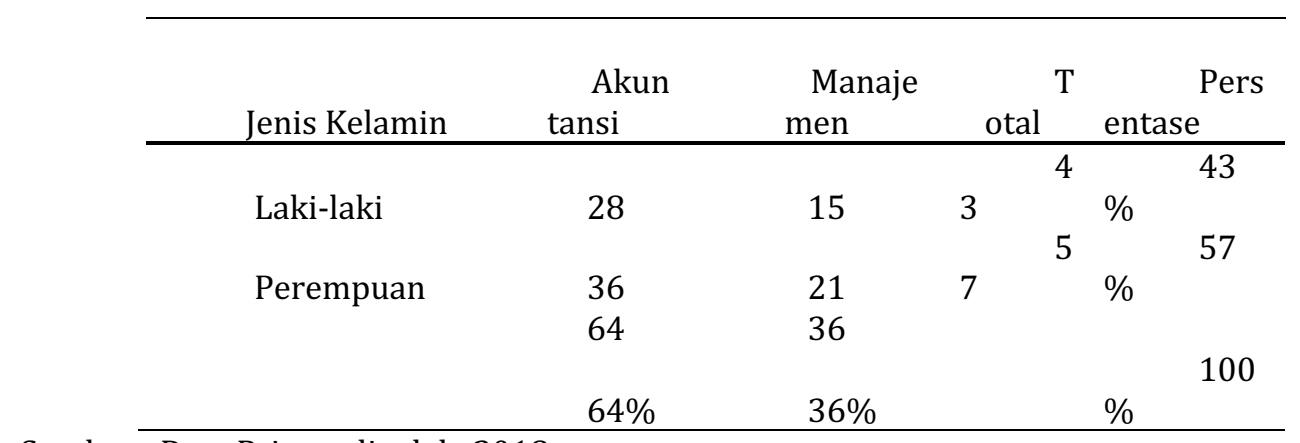

Sumber : Data Primer dioalah, 2018

Uji Instrumen Penelitian Uji Validitas dan Uji Reliabilitas.

Instrumen penelitian dapat dikatakan handal apabila instrument tersebut lolos dari uji validitas dan reliabilitas. Hasil kuesioner dikatakan valid apabila nilai korelasi antara masing-masing indicator dengan total skor menunjukkan hasil yang signifikan serta dikatakan reliabel apabila nilai Cornbach's Alpha > 0,60. Dari hasil uji validitas dan uji reliabilitas dengan menggunakan SPSS didapatkan nilai Cornbach's Alpha sebesar 0,69 serta semua nilai korelasi antara masing-masing indikator dengan total skor menunjukkan hasil yang signifikan seperti yang tersaji dalam tabel 2 berikut.

Tabel 2.

Hasi Uji Validitas dan Reliablitas

\begin{tabular}{cclc}
\hline Nilai uji & Nilai Uji & Kriteria & Keterangan \\
\hline $\begin{array}{l}\text { Cornbach's Alpha } \\
\begin{array}{l}\text { Korelasi indikator } \\
\text { dengan total skor }\end{array}\end{array}$ & 0,69 & $>0,6$ & Reliabel \\
\hline
\end{tabular}


Sumber : Data Primer diolah, 2018

Analisis Minat Mahasiswa Menjadi Wirausaha

Minat untuk menjadi wirausaha pada mahasiswa Fakultas Ekonomi Universitas Hindu Indonesia diukur dengan menggunakan pertanyaan dalam kuesioner dalam bentuk skala likert dari skala 1 sampai 5. (Keterangan 1 = Sangat Tidak Setuju, $2=$ Tidak Setuju, $3=$ Netral, $4=$ Setuju, $5=$ Sangat Setuju). Untuk memudahkan analisis maka hasil pengukuran akan dicari nilai rata-rata untuk tiap variabel yang kemudian akan dikelompokkan berdasarkan kategori yang tercantum pada Tabel 3 dan Tabel 4

Tabel 3.

Skala Pengukuran Minat Mahasiswa Menjadi Wirausaha

\begin{tabular}{ll}
\hline Skala & Keterangan \\
\hline $1,00-2,33$ & Tidak Setuju \\
$2,34-3,69$ & Cukup Setuju \\
$3,70-5,00$ & Sangat Setuju \\
\hline
\end{tabular}

Sumber : Data Primer diolah, 2018

Tabel 4

Hasil Pengukuran Minat Menjadi Wirausaha

\begin{tabular}{|c|c|c|}
\hline Indikator & Mean & Kriiteria \\
\hline Menjadi Wirausaha, dapat meningkatkan status sosial saya & 3.34 & Cukup Setuju \\
\hline Saya percaya pada kemampuan saya sendiri untuk mengambil risiko & 3.13 & Cukup Setuju \\
\hline $\begin{array}{l}\text { Menjadi Wirausaha, saya dapat menghasilkan hasil yang lebih dari } \\
\text { pekerjaan biasa. }\end{array}$ & 3.70 & Sangat Setuju \\
\hline Saya ingin memulai bisnis dari diri saya sendiri & 3.71 & Sangat Setuju \\
\hline $\begin{array}{l}\text { Menjadi Wirausaha, saya dapat menerima subsidi dan insentif } \\
\text { pemerintah }\end{array}$ & 3.12 & Cukup Setuju \\
\hline Saya sangat termotivasi oleh kisah sukses banyak pengusaha & 3.07 & Cukup Setuju \\
\hline Saya ingin menjadi pemberi pekerjaan daripada pencari kerja & 2.71 & Cukup Setuju \\
\hline $\begin{array}{l}\text { Saya ingin mewujudkan pengetahuan dan keterampilan profesional } \\
\text { saya }\end{array}$ & 3.16 & Cukup Setuju \\
\hline $\begin{array}{l}\text { Menjadi Wirausaha, saya bisa mendapatkan lebih banyak } \\
\text { pengalaman dalam dunia bisnis emosional }\end{array}$ & 3.66 & Cukup Setuju \\
\hline
\end{tabular}

Sumber: Data Primer dioalah, 2018

Berdasarkan tabel 4 dapat dijelaskan bahwa dari total 9 pernyataan tentang minat berwirausaha, 2 indikator pernyataan mendapatkan kategori sangat setuju dan 7 indiktor cukup setuju. Dua (2) indiaktor dengan rata-rata tertinggi yaitu:

1) Saya ingin memulai bisnis saya sendiri

2) Menjadi Wirausaha, saya dapat menghasilkan hasil yang lebih dari pekerjaan biasa

Temuan menarik dari indiaktor minat menjadi wirausaha adalah berkaitan dengan memulai bisnis dan menghasilkan hasil yang lebih dari pekerjaan biasa. Bahwa memulai bisnis dari diri sendiri mempunyai pengaruh yang sangat kuat terhadap minat menjadi wirausaha, hal ini dikarenakan terdapat persepsi mahasiswa bahwa untuk memulai bisnis itu tidak mesti dengan menggunakan modal besar sehingga tidak perlu bergantung pada pihak lain. Hal menarik lainnya adalah adanya persepsi dari mahasiswa bahwa dengan berwirausaha akan menghasilkan hasil yang lebih dari pekerjaan biasa Hal ini menjadi motivasi bahwa masa depan mahasiswa tidak semata-mata mau menjadi pegawai negeri akan tetapi dengan berwirausaha akan mendapat pengahsilan lebih dari pekerjaan biasa bahkan sebagai PNS 
sekalipun. Kemungkinan juga mahasiswa terinspirasi adanya beberapa anak pejabat Negara mereka tidak malu untuk menjadi wirausaha muda.

Analisis Faktor

Untuk mengukur faktor-faktor utama yang mempengaruhi tingkat minat menjadi wirausaha, dapat digunakan analisis faktor dalam mereduksi data untuk mengidentifikasi sejumlah kecil faktor yang menjelaskan variabel yang berbeda. Asumsi yang harus dipenuhi dalam analisis faktor adalah:

1) Uji Determinant of Correlation Matrix. Matrik korelasi dikatakan antar variabel saling terkait apabila determinan bernilai mendekati nilai 0. Hasil perhitungan menunjukkan nilai Determinant of Correlation Matrix sebesar 0,006. Nilai ini mendekatai 0, dengan demikian matrik korelasi antara variabel saling terkait.

2) Melihat nilai KMO and Bartlett's Test

Hasil Pengujian membuktikan bahwa nilai KMO diperoleh sebesar 0,58 lebih besar dari 0,50 dengan demikian persyaratan KMO terpenuhi

3) Hasil perhitungan dengan SPSS dihasilkan nilai Barlett Test of Spehricity sebesar 494,142 dengan signifikansi sebesar 0,000. Dengan demikian Bartlett Test of Spehricity memenuhi persyaratan karena signifikansi di bawah 0,05 (5\%).

4)Pengujian persyaratan MSA terhadap 9 variabel, dijelaskan pada tabel di bawah ini: Hasil Uji Persyaratan MSA adalah nilai MSA $>0,5$ seperti yang tersaji dalam tabel 5 berikut.

Tabel 5

Hasil Perhitungan Uji MSA

\begin{tabular}{|c|c|c|}
\hline Indikator & MSA & Kriiteria \\
\hline Menjadi Wirausaha, dapat meningkatkan status sosial saya & 0,545 & Terpenuhi \\
\hline Saya percaya pada kemampuan saya sendiri untuk mengambil risiko & 0,398 & Tidak Terpenuhii \\
\hline $\begin{array}{l}\text { Menjadi Wirausaha, saya dapat menghasilkan hasil yang lebih dari } \\
\text { pekerjaan biasa. }\end{array}$ & 0,573 & Terpenuhi \\
\hline Saya ingin memulai bisnis dari diri saya sendiri & 0,766 & Terpenuhi \\
\hline $\begin{array}{l}\text { Menjadi Wirausaha, saya dapat menerima subsidi dan insentif } \\
\text { pemerintah }\end{array}$ & 0,563 & Terpenuhi \\
\hline Saya sangat termotivasi oleh kisah sukses banyak pengusaha & 0,613 & Terpenuhi \\
\hline Saya ingin menjadi pemberi pekerjaan daripada pencari kerja & 0,652 & Terpenuhi \\
\hline $\begin{array}{l}\text { Saya ingin mewujudkan pengetahuan dan keterampilan profesional } \\
\text { saya }\end{array}$ & 0,545 & Terpenuhi \\
\hline $\begin{array}{l}\text { Menjadi Wirausaha, saya bisa mendapatkan lebih banyak } \\
\text { pengalaman dalam dunia bisnis emosional }\end{array}$ & 0,600 & Terpenuhi \\
\hline
\end{tabular}

Sumber : Data Primer dioalah, 2018

Berdasarkan tabel 5 diperoleh 1 indikator yakni saya percaya pada kemampuan saya sendiri untuk mengambil risiko dengan nilai MSA sebesar 0,398 sehingga indikator ini harus dikeluarkan, sehingga diperoleh hasil sebagai berikut :

1) Uji Determinant of Correlation Matrix. Matrik korelasi dikatakan antar variabel saling terkait apabila determinan bernilai mendekati nilai 0. Hasil perhitungan menunjukkan nilai Determinant of Correlation Matrix sebesar 0,01. Nilai ini mendekatai 0, dengan demikian matrik korelasi antara variabel saling terkait.

2) Melihat nilai KMO and Bartlett's Test

Hasil Pengujian membuktikan bahwa nilai KMO diperoleh sebesar 0,609 lebih besar dari 0,50 dengan demikian persyaratan KMO terpenuhi

3)Hasil perhitungan dengan SPSS dihasilkan nilai Barlett Test of Spehricity sebesar 440,586 dengan signifikansi sebesar 0,000. Dengan demikian Bartlett Test of Spehricity memenuhi persyaratan karena signifikansi di bawah 0,05 (5\%). 
4)Pengujian persyaratan MSA terhadap 9 variabel, dijelaskan pada tabel di bawah ini: Hasil Uji Persyaratan MSA adalah nilai MSA > 0,5 seperti yang tersaji dalam tabel 6 berikut.

Tabel 6

Hasil Perhitungan Uji MSA

\begin{tabular}{lcc}
\hline \multicolumn{1}{c}{ Indikator } & MSA & Kriiteria \\
\hline $\begin{array}{l}\text { Menjadi Wirausaha, dapat meningkatkan status sosial saya } \\
\text { Menjadi Wirausaha, saya dapat menghasilkan hasil yang lebih dari } \\
\text { pekerjaan biasa. }\end{array}$ & 0,591 & Terpenuhi \\
$\begin{array}{l}\text { Saya ingin memulai bisnis dari diri saya sendiri } \\
\text { Menjadi Wirausaha, saya dapat menerima subsidi dan insentif }\end{array}$ & 0,752 & Terpenuhi \\
$\begin{array}{l}\text { pemerintah } \\
\text { Saya sangat termotivasi oleh kisah sukses banyak pengusaha }\end{array}$ & 0,572 & Terpenuhi \\
$\begin{array}{l}\text { Saya ingin menjadi pemberi pekerjaan daripada pencari kerja } \\
\text { Saya ingin mewujudkan pengetahuan dan keterampilan profesional } \\
\text { saya }\end{array}$ & 0,761 & Terpenuhi \\
$\begin{array}{l}\text { Menjadi Wirausaha, saya bisa mendapatkan lebih banyak } \\
\text { pengalaman dalam dunia bisnis emosional }\end{array}$ & 0,563 & Terpenuhi \\
\hline
\end{tabular}

Sumber : Data Primer diolah, 2018

Dari tabel 6 menujukkan bahwa 8 indikator minat menjadi mahasiswa memenuhi persyaratan komunalitas yaitu lebih besar dari 0,5 (komunalitas >0,5).

Setelah asumsi analisis faktor terpenuhi, maka langkah berikutnya adalah perhitungan eigenvalues ditampilkan di tabel 7 sebagai berikut:

Tabel 7

Hasil Perhitungan Initial Eigenvalues

\begin{tabular}{crrrrrr}
\hline & \multicolumn{3}{c}{ Initial Eigenvalues } & \multicolumn{2}{c}{ Extraction Sums of Squared Loadings } \\
\cline { 2 - 6 } Component & \multicolumn{1}{c}{ Total } & \% of Variance & Cumulative \% & Total & \% of Variance & Cumulative \% \\
\hline 1 & 2.799 & 34.983 & 34.983 & 2.799 & 34.983 & 34.983 \\
2 & 1.940 & 24.253 & 59.237 & 1.940 & 24.253 & 59.237 \\
3 & 1.162 & 14.520 & 73.756 & 1.162 & 14.520 & 73.756 \\
4 & .762 & 9.528 & 83.284 & & & \\
5 & .615 & 7.693 & 90.977 & & & \\
6 & .411 & 5.137 & 96.114 & & & \\
7 & .282 & 3.525 & 99.638 & & & \\
8 & .029 & .362 & 100.000 & & & \\
\hline
\end{tabular}

Sumber : Data Primer diolah, 2018

Dari hasil tersebut dilakukan reduksi indikator variabel menjadi 3 faktor, karena hasil dari pengelompokan 3 faktor sudah mencapai lebih dari $73 \%$ dan dapat mewakili sehingga diharapkan variabel-variabel dapat mengelompok menjadi 3 faktor untuk memudahkan analisa. Selanjutnya dicari loading factor menjadi 3 faktor seperti di tabel 7. Nilai pada tabel 7 adalah loading atau besar korelasi 
antara suatu variabel dengan 3 faktor. Variabel dikatakan secara nyata dapat masuk dalam sebuah faktor apabila nilai factor loadings lebih besar dari angka pembatas (cut off point) yaitu 0,50.

Tabel 7

Rotated Component Matrixa

\begin{tabular}{|c|c|c|c|}
\hline \multirow[b]{2}{*}{ Keterangan } & \multicolumn{3}{|c|}{ Component } \\
\hline & 1 & 2 & 3 \\
\hline Menjadi Wirausaha, dapat meningkatkan status sosial saya & .405 & .584 & .445 \\
\hline $\begin{array}{l}\text { Menjadi Wirausaha, saya dapat menghasilkan hasil yang lebih dari } \\
\text { pekerjaan biasa }\end{array}$ & .343 & .499 & .645 \\
\hline Saya ingin memulai bisnis dari diri saya sendiri & .787 & -.206 & .110 \\
\hline $\begin{array}{l}\text { Menjadi Wirausaha, saya dapat menerima subsidi dan insentif } \\
\text { pemerintah }\end{array}$ & .768 & -.590 & .077 \\
\hline Saya sangat termotivasi oleh kisah sukses banyak pengusaha & .513 & .506 & -.166 \\
\hline Saya ingin menjadi pemberi pekerjaan daripada pencari kerja & .454 & .462 & -.467 \\
\hline $\begin{array}{l}\text { Saya ingin mewujudkan pengetahuan dan keterampilan } \\
\text { profesional saya }\end{array}$ & .736 & -.610 & .053 \\
\hline $\begin{array}{l}\text { Menjadi Wirausaha, saya bisa mendapatkan lebih banyak } \\
\text { pengalaman dalam dunia bisnis }\end{array}$ & .544 & .344 & -.531 \\
\hline
\end{tabular}

Sumber : Data Primer diolah, 2018

Berdasarkan hasil dari tabel 7 maka langkah berikutnya adalah memberikan nama faktor pemicu minat menjadi wirausaha seperti yang tersaji dalam tabel 8 berikut.

Tabel 8

Faktor-faktor Pemicu Minat Menjadi Wirausaha

\begin{tabular}{|c|c|c|c|}
\hline \multirow[t]{2}{*}{ Faktor } & & Nama & Indikator \\
\hline & \multicolumn{3}{|l|}{ Engin Value } \\
\hline \multirow[t]{4}{*}{1} & 2,799 & Sikap & Saya ingin memulai bisnis dari diri saya sendiri \\
\hline & & & $\begin{array}{l}\text { Saya sangat termotivasi oleh kisah sukses banyak } \\
\text { pengusaha }\end{array}$ \\
\hline & & & Saya ingin mewujudkan pengetahuan dan \\
\hline & & & keterampilan profesional saya \\
\hline 2 & 1,940 & Image & $\begin{array}{l}\text { Menjadi Wirausaha, dapat meningkatkan status sosial } \\
\text { saya }\end{array}$ \\
\hline
\end{tabular}


Menjadi Wirausaha, saya dapat menerima subsidi dan insentif pemerintah

\begin{tabular}{|c|c|c|c|}
\hline 3 & 1,162 & $\begin{array}{l}\text { Motivasi } \\
\text { Keuangan }\end{array}$ & $\begin{array}{l}\text { Menjadi Wirausaha, saya dapat menghasilkan hasil } \\
\text { yang lebih dari pekerjaan biasa }\end{array}$ \\
\hline
\end{tabular}

Menjadi Wirausaha, saya bisa mendapatkan lebih banyak pengalaman dalam dunia bisnis

Sumber : Data Primer dioalah, 2018

Faktor yang mempunyai eigenvalue terbesar $(2,799)$ adalah faktor sikap yang meliputi 3 indikator yakni saya ingin memulai bisnis dari diri saya sendiri, saya sangat termotivasi oleh kisah sukses banyak pengusaha dan saya ingin mewujudkan pengetahuan dan keterampilan profesional saya. Faktor kedua adalah image/citra dengan eigenvalue sebesar 1,940 dengan 2 indikator yakni menjadi wirausaha, dapat meningkatkan status sosial dan menjadi wirausaha dapat menerima subsidi dan insentif pemerintah. Faktor ketiga adalah profit dengan eigenvalue sebesar 1,162 dengan 2 indikator yakni menjadi wirausaha, dapat menghasilkan hasil yang lebih dari pekerjaan biasa serta menjadi wirausaha, mendapatkan pengalaman lebih banyak dalam dunia bisnis.

Analisis Regresi Linier berganda digunakan untuk menguji sejauh mana pengaruh faktor-faktor yang dibentuk (score factor) sebagai variabel bebas terhadap niat menjadi wirausaha sebagai variabel terikat dapat ditunjukkan dengan tabel 9 berikut:

Tabel 9

Analisis Regresi

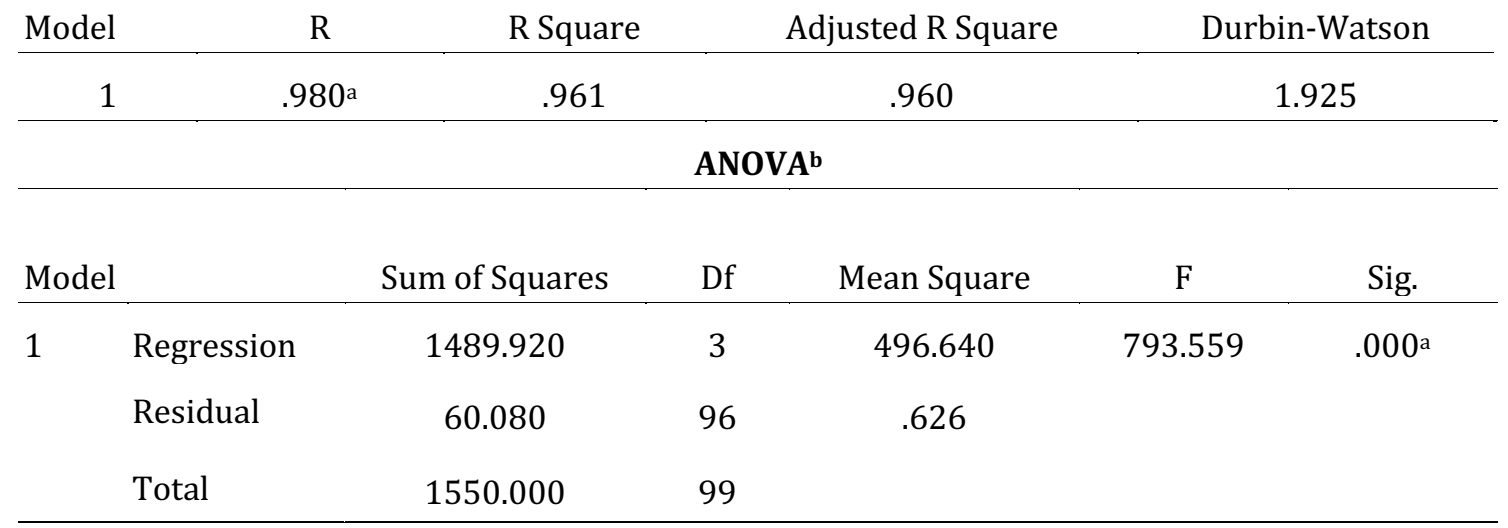

\begin{tabular}{|c|c|c|c|c|c|c|c|}
\hline & & $\mathrm{B}$ & Std. Error & Beta & & Sig. & VIF \\
\hline \multirow[t]{4}{*}{1} & (Constant) & 29.600 & .079 & & 374.163 & .000 & 1,0 \\
\hline & Sikap & 2.379 & .080 & .601 & 29.925 & .000 & 1,0 \\
\hline & Image & 2.308 & .080 & .583 & 29.025 & .000 & 1,0 \\
\hline & Motivasi Finansial & 2.016 & .080 & .509 & 25.351 & .000 & 1,0 \\
\hline
\end{tabular}

Sumber : Data Primer diolah, 2018 
Model regresi pada tabel 9 menunjukkan nilai R square sebesar 0,961, yang berarti bahwa 96,1\% variasi dalam minat mahasiswa menjadi wirausaha dapat dijelaskan oleh faktor-faktor yang terbentuk yakni sikap, image dan motivasi keuangan mempengaruhi niat. Asumsi klasik untuk menguji analisis regresi adalah nilai uji Durbin Watson diperoleh $1.925<2$. Tabel ANOVA memberikan nilai Uji F dengan nilai signifikansi (0.000) serta nilai VIF sebesar 1. Uji Normalitas juga memberikan nilai KolmogorovSmirnov $Z$ sebesar 1,215 dengan signifikansi > 0,5 yakni 0,104. Dengan demukian model regresi regresi faktor-faktor yang mempengaruhi minat mahasiswa menjadi wirausaha adalah valid. Hal ini menunjukkan bahwa sikap, image dan motivasi keuangan memiliki pengaruh positif dan signifikan terhadap minat mahasiswa menjadi wirausaha.

\section{Simpulan dan saran}

Dari hasil pembahasan dapat disimpulkan bahwa faktor-faktor yang mendorong minat mahasiswa khususnya di Universitas Hindu Indonesia menjadi wirausaha dapat dikelompokkan kedalam 3 faktor yakni sikap, image dan motivasi finansial. Temuan penelitian mengungkapkan bahwa mahasiswa memiliki siakp positif terhadap kewirausahaan. Sebagian besar dari mereka mempunyai persepsi bahwa menjadi wirausaha adalah ingin mengaplikasikan pengetahuan dan keterampilan professional. Hal ini berimplikasi terhadap penerapan kurikulum dan mata kualiah kewirausahaan dan juga pengembangan pelatihan kewirausahaan. Dengan demikian program-program kesadaran berwirausaha perlu dilaksanakan dengan lebih efisien dan efektif. Sehingga generasi kita selanjutnya akan menjadi penyedia lapangan kerja daripada pencari kerja

Adapun keterbatasan penelitian ini adalah penelitian ini hanya terbatas di satu Universitas sehingga validitas eksternal atau aspek generalisasi menjadi rendah Untuk penelitian berikutnya bisa dikembangkan ke berbagai universitas yang berada dibaawah Kopertis Wilayah VIII dengan mengembangkan lebih banyak indiaktor-indikator sebagai pemicu minat mahasiswa menjadi wirausaha.

\section{Daftar Rujukan}

Antony, Binu; Thomas, Deepu, 2018, The Entrepreneurial Capabilities And Inclinations Of College Students In Kerala P.G., Mirror Peer Refereed International Journal Vol.8 No.4-A , 192-199

Crant, J Michael.The proactive personality scale as a predictor of entrepreneurial intentions Journal of Small Business Management; Milwaukee Vol. 34, Iss. 3, (Jul 1996): 42

Douglas, E., (1999) Entrepreneurship as a career choice. Attitudes entrepreneurial intentions and utility maximizations, Frontiers of Entrepreneurship Research, Babson College, Wellesley

Lumpkin, G. T., \&Dess, G. G. (1996). The entrepreneurial clarifying it construct and linking orientation. Academy ofManagement Review, 21(1), 135-172.

Lee, S.H. \& Wong, P.K. 2004, An Exploratory Study of Technopreneurial Intentions: A Career Anchor Perspective, Journal of Business Venturing, 19 (1): 7-28.

Miller, D. (1983). The correlates of entrepreneurship in three types of firms. Management Science, 29, 770791

Milla. H. 2013, Pendidikan Kewirausahaan: Sebuah Alternatif Mengurangi Pengangguran Terdidik dan Pencegahan Korupsi, Jurnal AlTa'lim, Jilid 1, Nomor 6 Oktober 2018, pp 465-471

Oktarilis, N.S. 2012, Pengaruh Faktor-faktor yang dapat memotivasi mahasiswa berkeinginan wirausaha, Jurnal Entrepreneurship, repository.gunadarma.ac.id/bitstream/.../1/ Jurnal\%20Entrepreneurship.pdf, Diakses 1 Oktober 2018

Refer Robinson, S., \&Stubberud, H. A. (2014). Elements of entrepreneurial orientation and their relationship to entrepreneurial intent. Journal of Entrepreneurship Education, 17(2), 1-12.

Republika. 2016, RI Butuh Jutaan Wirausaha Baru, http://www.republika.co.id/berita/koran/ ekonomikoran/16/05/24/o7oh8614-ri-butuhjutaan-wirausaha-baru, Diakses pada 1 Oktober 2018 
Tirto, 2018, BPS: Pengangguran Lulusan Universitas Naik 1,13 Persen, https://tirto.id/bpspengangguran-lulusan-universitas-naik-113-persen-cJ3h, diakses 1 Oktober 2018

Widhari, C.I.S \& I.K. Suarta. 2012, Analisis Faktor-faktor yang Memotivasi Mahasiswa Berkeinginan Menjadi Wirausaha, Jurnal Bisnis dan Kewirausahaan Vol. 8, No. 1, Maret 2012.

Yurtkoru, E. S., Acar, P., \&Teraman, B. S. (2014). Willingness to take risk and entrepreneurial intention of university students: An empirical study comparing private and state universities. Procedia - Social and Behavioral Sciences,150(2014), 834-840. 